\title{
Mid-term efficacy and safety of cervical disc arthroplasty versus fusion in cervical spondylosis: A systematic review and meta-analysis
}

\author{
GUO-SHENG ZHAO ${ }^{1}$, QIAO ZHANG ${ }^{2}$ and ZHENG-XUE QUAN ${ }^{1}$ \\ Departments of ${ }^{1}$ Orthopaedics and ${ }^{2}$ Hematology, The First Affiliated Hospital \\ of Chongqing Medical University, Chongqing 400016, P.R. China
}

Received October 7, 2016; Accepted November 16, 2016

DOI: $10.3892 /$ br. 2016.823

\begin{abstract}
Anterior cervical discectomy and fusion (ACDF) and cervical disc arthroplasty (CDA) are the most commonly used procedures in cervical spondylosis. However, only a few published studies exist in the literature comparing these two operation types, particularly its mid-term efficacy and safety. Furthermore, in those studies, even large sample trials, when compared, have elicited controversial results, making it inconvenient for clinicians to refer to them. The aim of the present study was to clarify the advantages and shortcomings of the two procedures. Articles indexed in the PubMed, Web of Science, Cochrane Library, EMBASE, China Biological Medicine and China National Knowledge Infrastructure (CNKI) databases, as of March 2016, that met our criteria were searched. A total of 18 trials involving 3,040 patients were included in our final analysis. The most important results drawn from the present analysis were as follows: Insignificant differences were identified in the blood loss [weighted mean difference $(\mathrm{WMD})=6.23$; $95 \%$ confidence intervals $(\mathrm{CI}),-0.85$ to $13.32 ; \mathrm{P}=0.08$ ], surgical time [standardized mean difference $(\mathrm{SMD})=0.40 ; 95 \% \mathrm{CI}$, -0.01 to $0.82 ; \mathrm{P}=0.06]$, the time of hospital stay $(\mathrm{SMD}=0.05$; $95 \% \mathrm{CI},-0.28$ to $0.37 ; \mathrm{P}=0.77)$ and the total complications rate [odds ratio $(\mathrm{OR})=0.86 ; 95 \% \mathrm{CI}, 0.66$ to $1.131 ; \mathrm{P}=0.28$ ] on a comparison of the two operation methods. By contrast, comparing CDA with ACDF, the CDA had higher Short Form survey $(\mathrm{SF}-36)$ scores $(\mathrm{WMD}=1.65 ; 95 \% \mathrm{CI}, 0.61$ to 2.69 ; $\mathrm{P}=0.002)$, a larger range of motion in the operation level (SMD=6.53; 95\% CI, 3.89 to 9.17; $\mathrm{P}<0.0001$ ), a higher rate of neurological improvement following the operation $(\mathrm{OR}=1.80$; 95\% CI, 1.29 to 2.52; $\mathrm{P}=0.0006$ ), a lower Visual Analog Scale (VAS) score of neck pain (WMD=0.16; $95 \%$ CI, -0.28 to 0.05 ;
\end{abstract}

Correspondence to: Professor Zheng-Xue Quan, Department of Orthopaedics, The First Affiliated Hospital of Chongqing Medical University, No. 1 Youyi Road, Chongqing 400016, P.R. China E-mail: quanzx18@126.com

Key words: anterior cervical discectomy and fusion, cervical disc arthroplasty, cervical spondylosis, mid-term efficacy, prospective comparative trials, randomized controlled trials, systematic review
$\mathrm{P}=0.006)$ and arm pain $(\mathrm{WMD}=0.12 ; 95 \% \mathrm{CI},-0.24$ to -0.01 ; $\mathrm{P}=0.04)$. In addition, in the mid-term following the surgery, CDA had a lower Neck Disability Index (NDI; SMD=0.18; $95 \% \mathrm{CI},-0.28$ to $-0.07 ; \mathrm{P}=0.001)$ and a lower reoperation rate of adjacent levels $(\mathrm{OR}=0.54 ; 95 \% \mathrm{CI}, 0.35$ to $0.85 ; \mathrm{P}=0.007)$ compared with ACDF. Taken together, these results suggested that CDA and ACDF are efficient and safe methods for dealing with cervical spondylosis. However, with respect to certain specific indicators, such as the reoperation rate of adjacent levels following surgery, the former has several advantages.

\section{Introduction}

Cervical spondylosis is a degenerative disc disease. It has been reported that it may be identified in the majority of people aged over 50 years, and the most prevalent symptom of cervical spondylosis is pain in the neck and/or arms in China (1). Furthermore, the neck or arm pain caused by cervical spondylosis has become a worldwide health problem (2). In the USA, $\sim 14 \%$ of adults aged $\geq 18$ years have experienced or suffered from neck pain over the course of the last few months (3).

Anterior cervical discectomy and fusion (ACDF) has been widely used in clinical practice, and is accepted as the standard procedure in the treatment of cervical spondylosis. As one of the most important procedures in the treatment of cervical degenerative disease, it has the effect of not only relieving the spinal cord and the nerve roots' pressure, but also of reinforcing the stability of the cervical vertebrae. However, with the increased number of total operations being performed and the accumulation of follow-up information over time, several studies have reported certain adverse effects, including higher reoperation rates at adjacent levels $(4,5)$.

In 1966, Fernström (6) first introduced cervical disc arthroplasty (CDA) as an operational method in the treatment of cervical spondylosis, and it has been gradually accepted as an alternative and effective approach in the treatment of cervical spondylosis. However, over time, several studies have indicated certain untoward adverse effects resulting from this procedure, including increased neck and/or arm pain following the operation and heterotopic ossification $(7,8)$.

As the most commonly used procedures in cervical spondylosis, only a few studies have been published which compare 
these two operation types, particularly with respect to their mid-term efficacy and safety. In these studies, even large sample trials have generated controversial results with respect to each other $(9,10)$, making it inconvenient for clinicians to refer to them. Therefore, the aim of the present study and systematic review was to assess the advantages and shortcomings of the two operational methods, CDA and ACDF.

\section{Materials and methods}

Search strategy and selection criteria. According to the method of Cochrane guidelines (Cochrane Handbook for Systematic Reviews of Interventions, version 5.1.0; see www.handbook.cochrane.org), the electronic databases, PubMed, Web of Science, Cochrane library, EMBASE, the China Biological Medicine and China National Knowledge Infrastructure (CNKI), were carefully searched. Up to March 2016, the randomized controlled trials (RCTs) and prospective comparative trials (PCTs), including all languages that compared ACDF and CDA, were selected. The Boolean terms 'AND, 'OR' and 'NOT' were introduced to combine the key words, including 'anterior cervical discectomy and fusion', 'cervical disc arthroplasty', 'cervical spondylosis', 'mid-term efficacy', 'randomized controlled trial', 'prospective comparative trials', 'systematic review', 'cervical osteoarthritis', 'disease of vertebrae cervicales', 'fusion', 'arthrodesis', 'spine fusion', 'cervical disc replacement', 'degeneration disc disease', 'PCT', 'CDA', 'ACDF', 'RCTs' and 'PCTs'.

Inclusion criteria were as follows: RCTs and PCTs in all languages that compared CDA with $\mathrm{ACDF}$ in the treatment of cervical osteoarthritis; either gender (male or female); the patient was aged 18 years or above with cervical osteoarthritis; there was at least 24 months' postoperative follow-up; and at least one of the following indexes were included: The Short Form survey (SF-36) score, range of motion (ROM) in the operation level, Visual Analog Scale (VAS) of neck and/or arm pain, Neck Disability Index (NDI), the reoperation rate of adjacent levels following surgery, the rate of neurologic improvement, surgical parameters (age of patients, blood loss, hospital stay and surgical time) and the total complication rate.

Exclusion criteria were as follows: Infection, presentation of bone tumors for CDA/ACDF surgical treatment, non-RCTs or non-PCT trials, severely cervical spinal stenosis, and reoperation cases.

Assessment of the studies' quality. Following the Cochrane collaboration guidelines (Cochrane Handbook for Systematic Reviews of Interventions version 5.1.0), the quality of the studies was independently assessed by two authors. The quality of these trials was assessed in seven aspects, including selection bias (predominantly to judge the generation of random sequence and allocation concealment), performance bias (to evaluate the blinding of participants and personnel) and attrition bias (to evaluate the degree of the incomplete outcome data), together with other biases.

Combination data and meta analysis. Review Manager (RevMan) 5.2.0 software was used to analyze the data. The predominant outcomes extracted from these trials were as

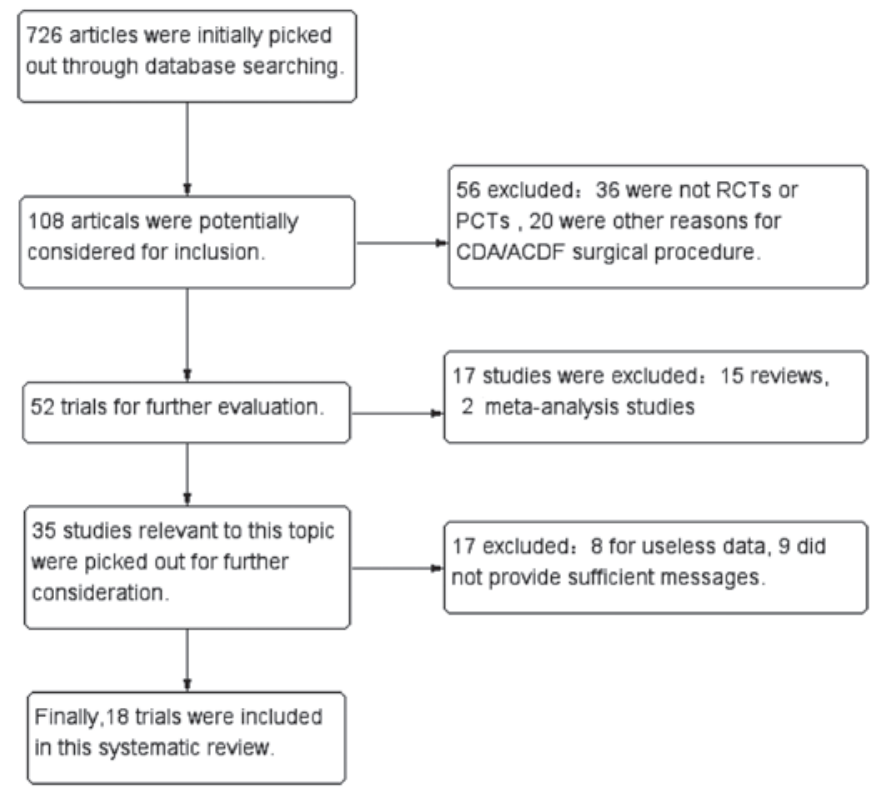

Figure 1. Flow chart illustrating the inclusion and exclusion criteria for the study.

follows: Age of the patients, blood loss, SF-36 score, VAS of neck and/or arm pain following the surgery, ROM at the operation level, NDI following surgery, and the reoperation rate of adjacent levels following surgery.

The heterogeneity was assessed using the chi-square test and I-square statistics (11). Fixed effect models $(\mathrm{P}<0.01$, $\mathrm{I}^{2} \leq 50 \%$ ) were used when there was insignificant heterogeneity; otherwise, the random effect models (when $\mathrm{P} \leq 0.01, \mathrm{I}^{2}>50 \%$ ) were applied. Odds ratio (OR; relative risk) combined with 95\% confidence intervals (CIs ) was used to describe the data of binary variables. For the continuous variables, the weighted mean difference (WMD or standard mean difference (SMD) with 95\% CIs were applied. Begg's and Egger's tests $(12,13)$ using Stata version 12.0 software (StataCorp, College Station, TX, USA) were introduced to test the publication bias of the main marker of the reoperation rate of adjacent levels following surgery. Sensitivity (14) and cumulative (15) analyses were also performed to assess the stability of the main indicators. $\mathrm{P}<0.05$ was considered to indicate a statistically significant value.

\section{Results}

Results of the included online searches and their quality evaluation. According to the search strategies previously undertaken by our group, 726 articles were selected first of all. In accordance with the exclusion and inclusion criteria, as specified above, two authors read the titles and abstracts independently. A total of 12 RCTs $(9,10,16-25)$ and six PCTs (26-31), including 3,040 patients (1,588 treated with CDA and 1,452 with ACDF) were finally included in the present systematic review (Fig. 1).

The Cochrane Collaboration rating system was used to evaluate the risks of the included trials. There were seven evaluation indexes, each of which had three levels, according to this rating system: Low risk (denoted with '+'), high risk 


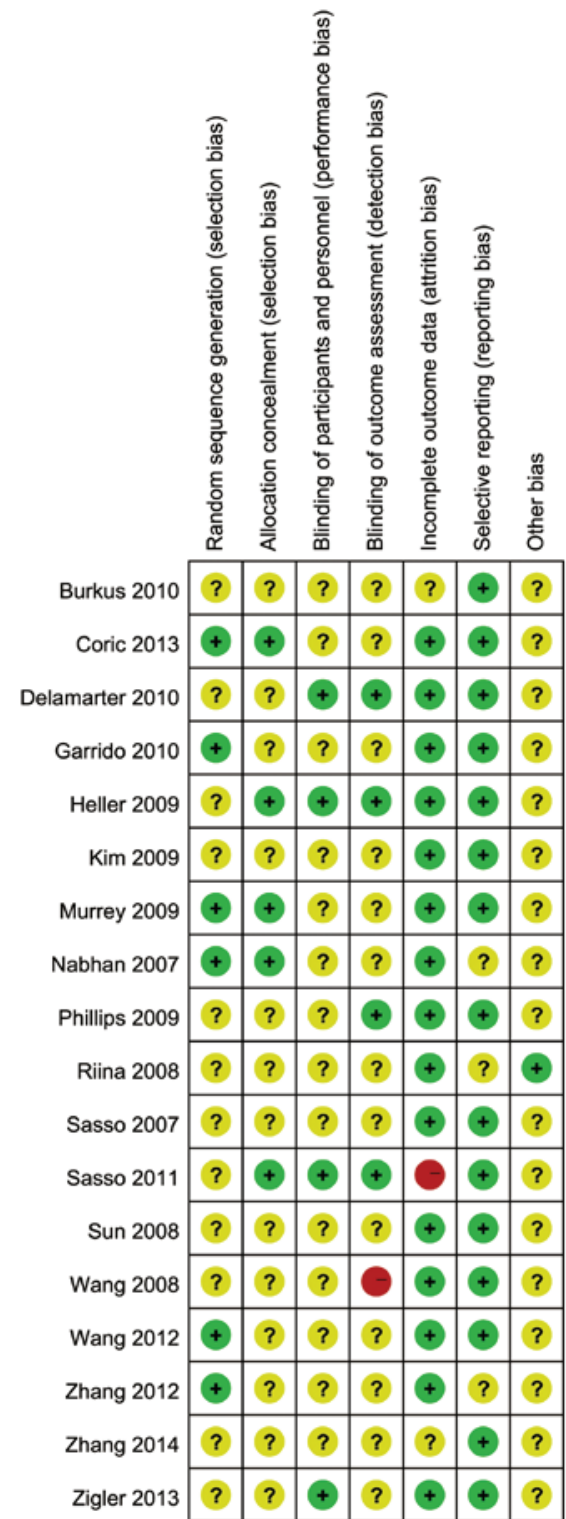

Figure 2. Results of an assessment of the risk of bias for the study (according to the Cochrane Collaboration rating system), as included in the system review.

(denoted with '-'), and unclear risk (denoted with '?'). The results are shown in Figs. 2 and 3.

Age of the patients and the blood loss during the surgery. Of the studies that were included, five of the trials reported detailed data of the patients, including the standard deviation (SD) and the mean of the ages. The combined results indicated that the differences between two groups were not statistically different (WMD=0.96; 95\% CI, 2.10 to 0.17 ; $\mathrm{P}=0.10$ ). In addition, no significant differences were identified for the heterogeneity tests $\left(\mathrm{I}^{2}=0 \% ; \mathrm{P}=0.77\right)$, as shown in Fig. 4 .

The volume of blood loss during the operation was assessed in six trials. From the combing results, no statistical significance was observed with the WMD (WMD=6.23; 95\% CI, 0.85 to $13.32 ; \mathrm{P}=0.08)$, and moderate heterogeneity was identified among the trials $\left(\mathrm{I}^{2}=38 \% ; \mathrm{P}=0.15\right)$ (Fig. 4).

Operation time and hospital stay. Six trials provided the necessary data on the mean operation time and the SD. The overall estimate revealed no significant difference for the two procedures with respect to this indicator $(\mathrm{SMD}=0.40 ; 95 \% \mathrm{CI}$, -0.01 to $0.82 ; \mathrm{P}=0.06)$. The heterogeneity of the studies was determined to be significant $\left(\mathrm{I}^{2}=81 \%\right.$; $\left.\mathrm{P}<0.0001\right)$, as shown in Fig. 5.

Adequate data concerning the hospital stay were available in five of the studies, and the comprehensive statistics revealed no significant differences between CDA and ACDF (SMD $=0.05 ; 95 \% \mathrm{CI},-0.28$ to $0.371 \mathrm{P}=0.77$ ), although there was moderate heterogeneity between them $\left(\mathrm{I}^{2}=73 \% ; \mathrm{P}=0.005\right)$, as shown in Fig. 5.

SF-36 score and VAS score following surgery at a mid-term follow-up. SF-36 scores were available in six of the studies with at least 24 months' follow-up. The overall results indicated that the CDA group had the higher $\mathrm{SF}-36$ scores (WMD=1.65; $95 \% \mathrm{CI}, 0.61-2.69 ; \mathrm{P}=0.002)$. The heterogeneity between these studies was moderate $\left(\mathrm{I}^{2}=34 \%, \mathrm{P}=0.18\right)$, as shown in Fig. 4 .

A VAS score of neck pain with at least 24 months' follow-up following the operation was identified from ten trials, and the comprehensive statistics indicated that the CDA procedure had the lower VAS score of neck pain $(\mathrm{WMD}=0.16 ; 95 \% \mathrm{CI}$, -0.28 to $-0.05 ; \mathrm{P}=0.006)$, and that moderate heterogeneity was observed between the CDA and ACDF groups $\left(\mathrm{I}^{2}=38 \%\right.$; $\mathrm{P}=0.11$ ), as shown in Fig. 4.

Nine trials were concerned with the VAS scores of arm pain with at least 24 months' follow-up, and the pool statistics revealed that the CDA procedure was associated with less arm pain (WMD $=-0.12 ; 95 \% \mathrm{CI},-0.24$ to $-0.01 ; \mathrm{P}=0.04$ ) with moderate heterogeneity observed between the CDA and ACDF groups $\left(\mathrm{I}^{2}=46 \% ; \mathrm{P}=0.06\right)$, as shown in Fig. 4 .

NDI and ROM at the operational level at a mid-term follow-up. Data regarding the NDI on a mid-term follow-up (at least 24 months' follow-up) following the surgery were available in 14 of the trials. The comprehensive statistics showed that CDA had the lower NDI (SMD=-0.18; 95\% CI, -0.28 to $-0.07 ; \mathrm{P}=0.001)$. Furthermore, the heterogeneity between the CDA and ACDF groups was insignificant $\left(\mathrm{I}^{2}=21 \%\right.$; $\left.\mathrm{P}=0.23\right)$, as shown in Fig. 5 .

Data concerning the ROM at the operational level (24 or more months' follow-up) were available in seven of the studies. The overall results indicated that the CDA had a larger ROM at the operational level $(\mathrm{SMD}=6.53 ; 95 \% \mathrm{CI}, 3.89$ to 9.17 ; $\mathrm{P}<0.0001)$. The level of heterogeneity was significant among the trials $\left(\mathrm{I}^{2}=98 \% ; \mathrm{P}<0.00001\right)$, as shown in Fig. 5 .

Rate of neurological improvement following the operation at a mid-term follow-up. The rate of neurological improvement following the operation was obtained from eight of the studies. Overall, the pool statistics indicated that there was a significant difference in favor of the CDA group $(\mathrm{OR}=1.80$; $95 \%$ CI 1.29 to $2.52 ; \mathrm{P}=0.0006$ ), although the heterogeneity test revealed an insignificant difference $\left(\mathrm{I}^{2}=0 \% ; \mathrm{P}=0.76\right)$, as shown in Fig. 6.

Total complications rate and the reoperation rate of adjacent levels following surgery in a mid-term follow-up. A total of 13 trials involving 2,583 patients provided detailed information about the total complications rate following surgery in a 


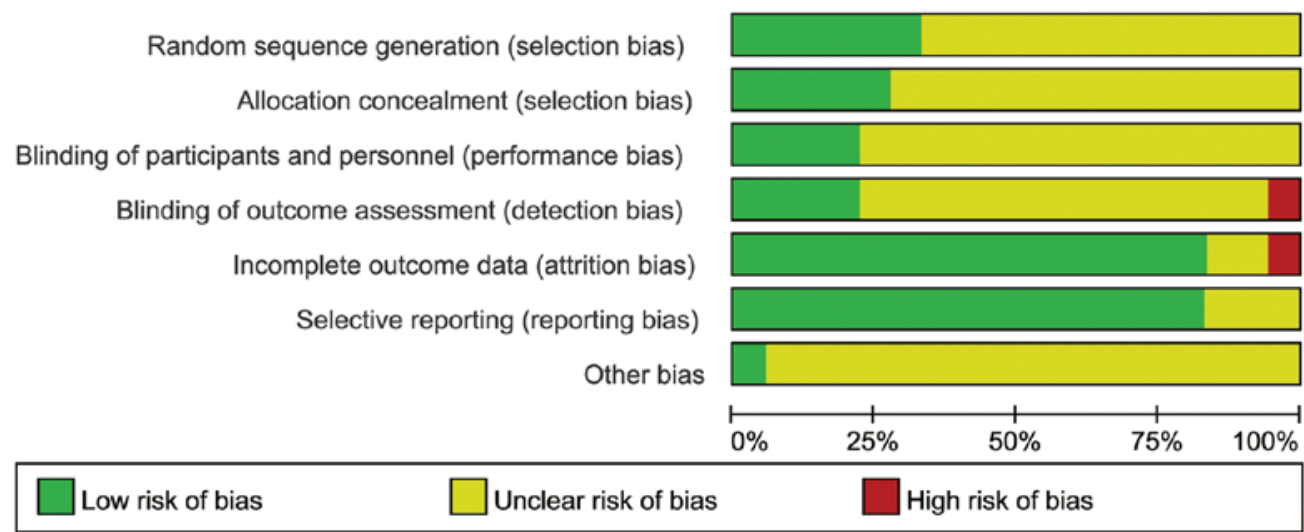

Figure 3. The percentages of the featured biases of all the included studies.

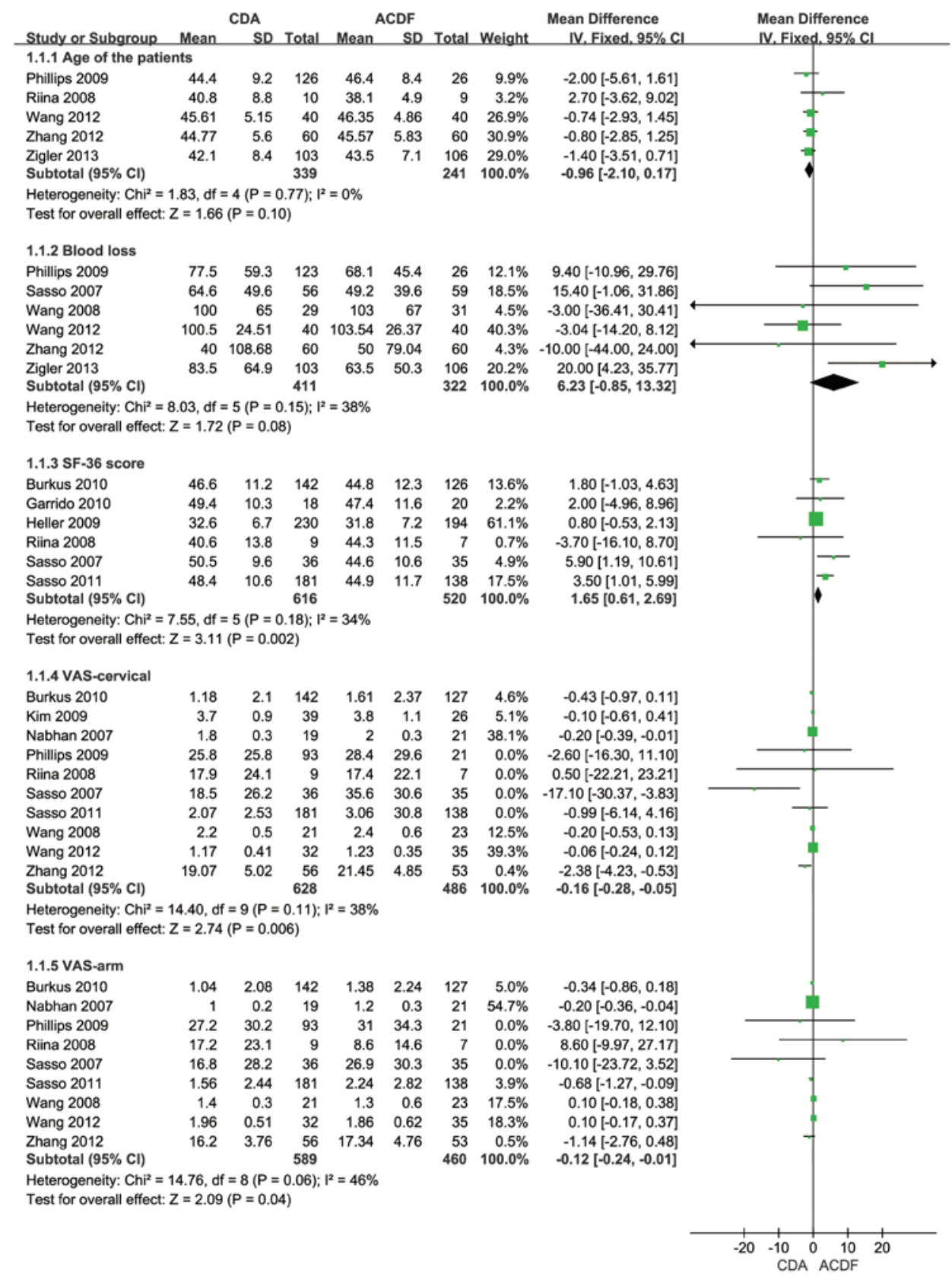

Figure 4. Forest plot (fixed effects model) illustrating the age of the patients, the blood loss during the surgery, and the SF-36 and VAS scores of neck/arm pain following the operation of meta analysis, comparing CDA with ACDF. CDA, cervical disc arthroplasty; ACDF, anterior cervical discectomy and fusion; Short Form survey (SF-36); VAS, Visual Analog Scale; CI, confidence interval. 


\begin{tabular}{|c|c|c|c|c|c|c|c|c|c|c|}
\hline \multirow[b]{2}{*}{ Study or Subgroup } & \multicolumn{3}{|c|}{ CDA } & \multicolumn{2}{|r|}{ ACDF } & & & \multirow{2}{*}{$\begin{array}{l}\text { Std. Mean Difference } \\
\text { IV. Random. } 95 \% \mathrm{Cl}\end{array}$} & \multirow{2}{*}{\multicolumn{2}{|c|}{$\begin{array}{l}\text { Std. Mean Difference } \\
\text { IV. Random. } 95 \% \mathrm{CI}\end{array}$}} \\
\hline & Mean & SD & Total & Mean & SD & Total & Weight & & & \\
\hline \multicolumn{11}{|l|}{ 2.1.1 Surgical time } \\
\hline Phillips 2009 & 95.5 & 37.5 & 124 & 97.4 & 32.1 & 26 & $17.5 \%$ & $-0.05[-0.47,0.37]$ & & \\
\hline Sasso 2007 & 102 & 30 & 56 & 66 & 24 & 59 & $17.8 \%$ & $1.32[0.92,1.73]$ & $=$ & \\
\hline Sun 2008 & 130 & 50 & 12 & 105 & 53 & 12 & $11.7 \%$ & $0.47[-0.34,1.28]$ & $=$ & \\
\hline Wang 2008 & 94 & 36.8 & 28 & 87 & 33 & 31 & $16.1 \%$ & $0.20[-0.31,0.71]$ & + & \\
\hline Wang 2012 & 94.23 & 22.25 & 40 & 87.68 & 20.32 & 40 & $17.2 \%$ & $0.30[-0.14,0.75]$ & $=$ & \\
\hline Zigler 2013 & 107.2 & 35.7 & 103 & 98.7 & 47 & 106 & $19.6 \%$ & $0.20[-0.07,0.47]$ & & \\
\hline Subtotal $(95 \% \mathrm{Cl})$ & & & 363 & & & 274 & $100.0 \%$ & $0.40[-0.01,0.82]$ & 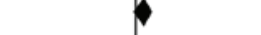 & \\
\hline \multicolumn{11}{|c|}{$\begin{array}{l}\text { Heterogeneity: } \mathrm{Tau}^{2}=0.21 ; \mathrm{Chi}^{2}=27.01, \mathrm{df}=5(\mathrm{P}<0.0001) ; \mathrm{I}^{2}=81 \% \\
\text { Test for overall effect: } Z=1.91(P=0.06)\end{array}$} \\
\hline \multicolumn{11}{|l|}{ 2.1.2 Hospital stay } \\
\hline Sasso 2007 & 0.9 & 0.4 & 56 & 0.6 & 0.6 & 59 & $20.5 \%$ & $0.58[0.21,0.96]$ & $=$ & \\
\hline Wang 2008 & 6.1 & 3.9 & 28 & 6.7 & 4 & 31 & $16.6 \%$ & $-0.15[-0.66,0.36]$ & & \\
\hline Wang 2012 & 6.13 & 1.27 & 40 & 6.72 & 0.96 & 40 & $18.4 \%$ & $-0.52[-0.97,-0.07]$ & $=$ & \\
\hline Zhang 2012 & 3.32 & 0.79 & 60 & 3.2 & 1.02 & 60 & $21.0 \%$ & $0.13[-0.23,0.49]$ & & \\
\hline Zigler 2013 & 1.4 & 1.18 & 103 & 1.3 & 0.83 & 106 & $23.5 \%$ & $0.10[-0.17,0.37]$ & & \\
\hline Subtotal $(95 \% \mathrm{Cl})$ & & & 287 & & & 296 & $100.0 \%$ & $0.05[-0.28,0.37]$ & & \\
\hline \multicolumn{11}{|c|}{ Heterogeneity: $\mathrm{Tau}^{2}=0.10 ; \mathrm{Chi}^{2}=14.71, \mathrm{df}=4(P=0.005) ;\left.\right|^{2}=73 \%$} \\
\hline \multicolumn{11}{|c|}{ Test for overall effect: $Z=0.30(P=0.77)$} \\
\hline \multicolumn{11}{|c|}{ 2.1.3 Neck Disability Index, NDI } \\
\hline Burkus 2010 & 16.5 & 19.6 & 144 & 21.4 & 20.2 & 127 & $13.0 \%$ & $-0.25[-0.49,-0.01]$ & & \\
\hline Delamarter 2010 & 20.3 & 18.6 & 65 & 21.2 & 14.9 & 49 & $6.8 \%$ & $-0.05[-0.42,0.32]$ & & \\
\hline Garrido 2010 & 10.1 & 11.4 & 18 & 15.9 & 13.2 & 20 & $2.6 \%$ & $-0.46[-1.10,0.19]$ & - & \\
\hline Heller 2009 & 16.2 & 11.5 & 230 & 19.2 & 13.4 & 194 & $17.0 \%$ & $-0.24[-0.43,-0.05]$ & & \\
\hline Kim 2009 & 7.6 & 0.9 & 39 & 7.2 & 1.6 & 26 & $4.1 \%$ & $0.32[-0.18,0.82]$ & & \\
\hline Murrey 2009 & 21.4 & 20.2 & 103 & 20.5 & 18.4 & 106 & $11.0 \%$ & $0.05[-0.22,0.32]$ & & \\
\hline Phillips 2009 & 10.8 & 10.5 & 91 & 11.7 & 10.5 & 21 & $4.5 \%$ & $-0.09[-0.56,0.39]$ & & \\
\hline Riina 2008 & 18.9 & 16.8 & 10 & 22.3 & 13.5 & 9 & $1.4 \%$ & $-0.21[-1.12,0.69]$ & - & \\
\hline Sasso 2007 & 11.6 & 15.6 & 36 & 23.1 & 18.6 & 35 & $4.4 \%$ & $-0.66[-1.14,-0.18]$ & - & \\
\hline Sasso 2011 & 13.2 & 16.1 & 181 & 19.8 & 20 & 138 & $14.2 \%$ & $-0.37[-0.59,-0.14]$ & & \\
\hline Wang 2008 & 8.9 & 4.5 & 21 & 8.4 & 5.1 & 23 & $3.0 \%$ & $0.10[-0.49,0.69]$ & & \\
\hline Wang 2012 & 16.83 & 3.12 & 32 & 17.21 & 3.53 & 35 & $4.4 \%$ & $-0.11[-0.59,0.37]$ & & \\
\hline Zhang 2012 & 14.89 & 2.9 & 56 & 15.25 & 3.77 & 53 & $6.7 \%$ & $-0.11[-0.48,0.27]$ & & \\
\hline Zhang 2014 & 19.04 & 7.04 & 55 & 20.1 & 9.58 & 56 & $6.8 \%$ & $-0.13[-0.50,0.25]$ & & \\
\hline Subtotal $(95 \% \mathrm{Cl})$ & & & 1081 & & & 892 & $100.0 \%$ & $-0.18[-0.28,-0.07]$ & & \\
\hline \multicolumn{11}{|c|}{ Heterogeneity: $\mathrm{Tau}^{2}=0.01 ; \mathrm{Chi}^{2}=16.36, \mathrm{df}=13(P=0.23) ; \mathrm{I}^{2}=21 \%$} \\
\hline \multicolumn{11}{|c|}{ Test for overall effect: $Z=3.21(P=0.001)$} \\
\hline \multicolumn{11}{|c|}{ 2.1.4 Range of motion (operation level) } \\
\hline Coric 2013 & 8.6 & 1.08 & 41 & 1.2 & 0.03 & 32 & $13.9 \%$ & $9.03[7.45,10.60]$ & & $\longrightarrow$ \\
\hline Kim 2009 & 12.1 & 2 & 39 & 2.3 & 0.8 & 26 & $14.2 \%$ & $5.93[4.77,7.09]$ & & \\
\hline Sasso 2011 & 8.5 & 1.31 & 181 & 1.1 & 0.17 & 138 & $14.5 \%$ & $7.43[6.81,8.05]$ & & $=$ \\
\hline Sun 2008 & 11.2 & 3.9 & 12 & 11.4 & 4.9 & 12 & $14.5 \%$ & $-0.04[-0.84,0.76]$ & & \\
\hline Wang 2012 & 6.35 & 1.45 & 32 & 1.26 & 0.23 & 35 & $14.4 \%$ & $4.96[3.97,5.95]$ & & \\
\hline Zhang 2012 & 8.79 & 0.89 & 56 & 0.79 & 0.63 & 53 & $14.0 \%$ & $10.26[8.82,11.69]$ & & $\rightarrow$ \\
\hline Zigler 2013 & 8.14 & 1.21 & 103 & 1.02 & 0.13 & 106 & $14.4 \%$ & $8.30[7.45,9.15]$ & & \\
\hline Subtotal $(95 \% \mathrm{Cl})$ & & & 464 & & & 402 & $100.0 \%$ & $6.53[3.89,9.17]$ & & \\
\hline \multicolumn{11}{|c|}{$\begin{array}{l}\text { Heterogeneity: } \mathrm{Tau}^{2}=12.39 ; \mathrm{Ch}^{2}=319.96, \mathrm{df}=6(P<0.00001) ; \mathrm{I}^{2}=98 \% \\
\text { Test for overall effect: } Z=4.84(P<0.00001)\end{array}$} \\
\hline
\end{tabular}

Figure 5. Forest plot (random effects model) illustrating the surgical time, the hospital stay, the NDI and the ROM in operation level of systematic review, comparing CDA with ACDF. CDA, cervical disc arthroplasty; ACDF, anterior cervical discectomy and fusion; NDI, Neck Disability Index; CI, confidence interval.

mid-term follow-up. From the final results it was possible to conclude that there was an insignificant difference between the CDA and ACDF groups (OR=0.86; 95\% CI, 0.66-1.13; $\mathrm{P}=0.28)$, and the result of the heterogeneity test was moderate $\left(\mathrm{I}^{2}=23 \% ; \mathrm{P}=0.21\right)$, as shown in Fig. 6 .

Data regarding the reoperation rate of adjacent levels following surgery in a mid-term follow-up was available in 14 trials. Overall, the comprehensive statistics indicated that the CDA procedure had a lower reoperation rate of adjacent levels following surgery $(\mathrm{OR}=0.54 ; 95 \% \mathrm{CI}, 0.35$ to 0.85 ;
$\mathrm{P}=0.007)$, with insignificant heterogeneity bias $\left(\mathrm{I}^{2}=0 \%\right.$; $\mathrm{P}=0.75$ ), as shown in Fig. 6 .

The test of publication bias and sensitivity and cumulative analysis. For the reoperation rate of adjacent levels following surgery, Stata version 12.0 software (StataCorp) was used to test the publication bias (Begg's and Egger's tests). The results of the Begg's test was $\operatorname{Pr}>|z|=0.373$ (continuity corrected), and the outcome of the Egger's test was 0.057, the two tests revealing that there was insignificant publication bias in this 


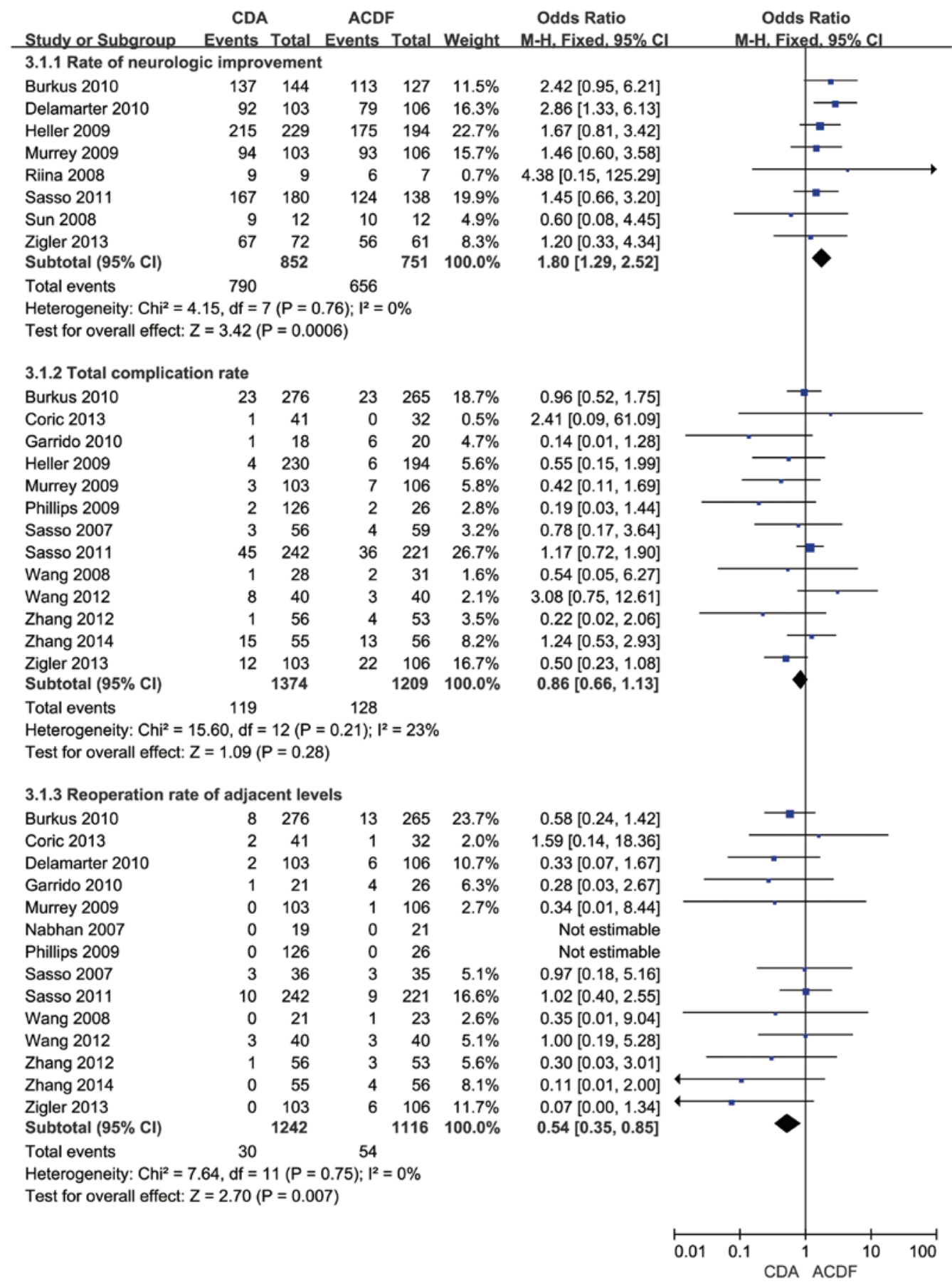

Figure 6. Forest plot illustrating the neurological improvement, total complications rate and the reoperation rate of adjacent levels following surgery, using a meta-analysis comparing CDA with ACDF. CDA, cervical disc arthroplasty; ACDF, anterior cervical discectomy and fusion; CI, confidence interval.

index. Funnel plots were also introduced to illustrate the publication bias of the reoperation rate of adjacent levels following surgery, as shown in Fig. 7.

In order to explore the influence of each trial on the pooled OR, sensitivity analysis was applied. The final statistical results were not materially altered by the elimination of any trials in the reoperation rate of adjacent levels following surgery, as shown in Fig. 8.

For the main indicator of the reoperation rate of adjacent levels following surgery, cumulative analysis was also performed according to the publication year of these trials. The results revealed a stable trend over time, as shown in Fig. 9.

\section{Discussion}

To date, two procedures have predominantly featured in cervical intervertebral disc surgery: ACDF and CDA. ACDF was first introduced in the 1950s, and since then, this method has been accepted as a standard procedure by numerous clinical doctors and scholars in order to treat the disease of vertebrae cervicales. It has been well established that ACDF has the apparent effect of not only relieving the spinal cord and the nerve roots' pressure, but also of reinforcing the cervical vertebrae's stability. However, it is associated with several side effects, including a high rate of reoperation of adjacent 


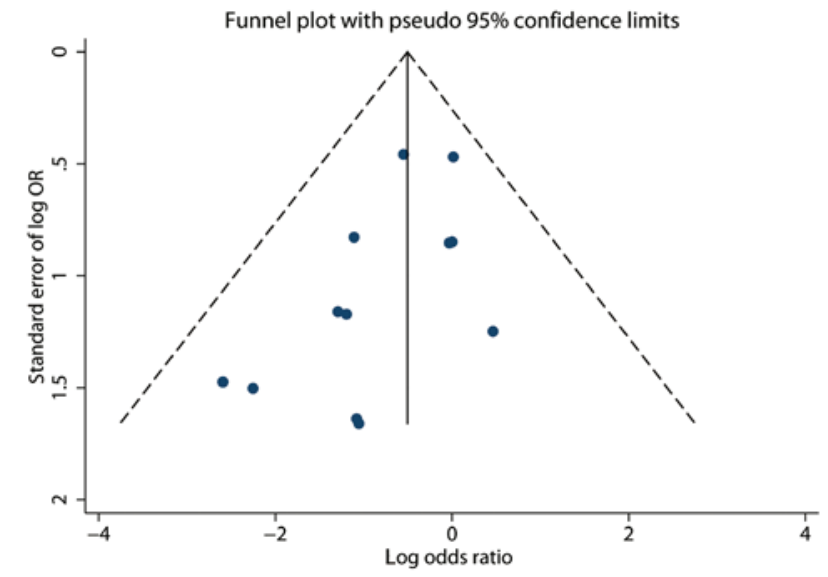

Figure 7. Funnel plots illustrating the publication bias of the reoperation rate of adjacent levels following surgery. OR, odds ratio.

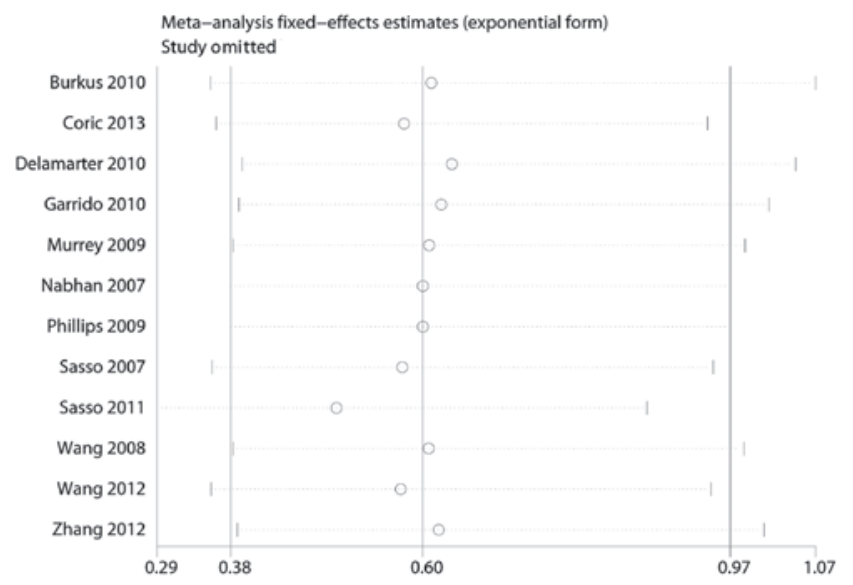

Figure 8. Analysis of the influence of summary odds ratio coefficients of the reoperation rate of adjacent levels following surgery.

level following operation (4). Goffin et al (32) identified that $\sim 6-10 \%$ of the patients who were admitted for the ACDF treatment required the operation to be performed again in the long run. The other procedure, CDA, was first introduced by Fernstrom (6) in 1966. Since then, other types of artificial cervical intervertebral disks have been manufactured, including the Bristol/Cummins (33), Prestige I, Prestige II, Prestige ST, Bryan, PCM and CerviCore devices. However, CDA remains one of the most widely accepted candidates for selection in order to treat cervical spondylosis. In addition, with the passage of time, several published studies have revealed that there are certain untoward reactions associated with this procedure, including heterotopic ossification, which may limit the ROM of the operation segment following the surgery $(7,8)$.

Several meta analysis studies (34-36) have already been performed to compare the efficacy and safety of CDA with ACDF for the treatment of cervical spondylosis. However, the majority of these included studies with short-term follow-up. In order to compare the therapeutic effects of these two operation procedures, particularly with respect to their mid-term efficacy and safety, the present systematic review was performed, which included more recently published studies with a longer follow-up.

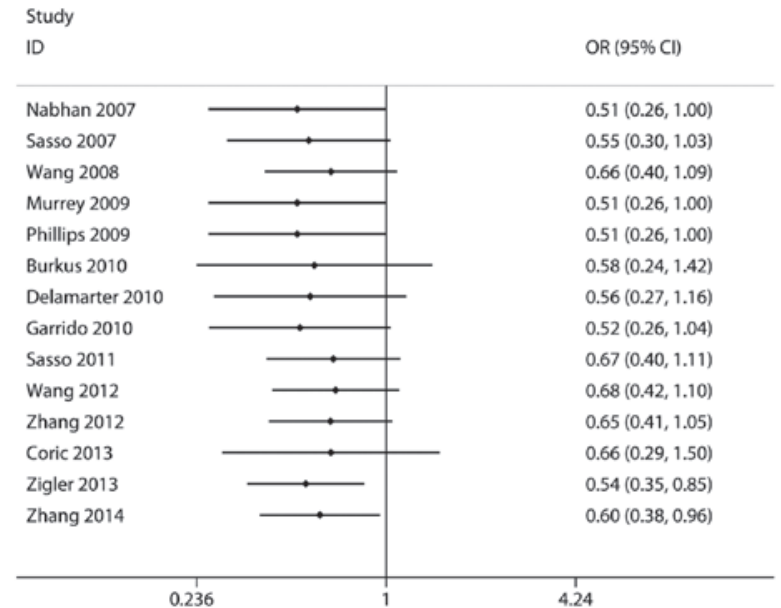

Figure 9. Cumulative analysis of the reoperation rate of adjacent levels following surgery (as a measure of the year of publication). OR, odds ratio; CI, confidence interval.

In the present study, several important indicators were analyzed to assess the efficacy of these two procedures after the mid-term follow-up (at least 24 months). The results indicated that, following mid-term follow-up, CDA had a higher SF-36 score, larger ROM at the operational level and a superior rate of neurological improvement. Furthermore, with respect to other important indices for evaluation of the effectiveness of CDA and ACDF, the former was associated with an inferior score of VAS in neck/arm pain and a lower NDI following the surgery.

To measure the safety of the two procedures, a few important indicators were assessed in the present study after the 24 months (or longer) follow-up. The results demonstrated that the prosthesis remained in a good working condition to preserve the motion at the site of surgery, and the CDA method was associated with a lower reoperation rate of adjacent levels. By contrast, with respect to the rate of the total complications in the mid-term follow-up, no significant differences were observed between the two operational methods.

In our meta analysis, insignificant differences between the two methods were observed for other important indicators, including the age of the patients, blood loss during the operation and hospital stay. However, a previously published meta analysis revealed that the CDA group had a longer operative time and more blood loss compared with the ACDF group (34). To interpret these differences, one may surmise that, as the number of total operations of CDA has increased over time, the longer operative times and enhanced levels of blood loss for arthroplasty reported in the study of Gao et al (34) may be attributable to the fact that CDA was, at that time, a novel technique that had not undergone the improvements that have now been implemented. Our results indicated that CDA and ACDF were efficient procedures in the mid-term follow-up.

Finally, in order to check the stability of the predominant indicators, Begg's and Egger's tests, sensitivity and cumulative analyses were performed. With regard to the predominant data (the reoperation rate of adjacent levels following surgery), the results of the cumulative test, sensitivity analysis and the shape of the Funnel plots all verified the reliability of the results in the present study. 
The present study had several limitations. First, only 12 RCTs met our criteria and were therefore finally included. Secondly, the follow-up period obtained from the studies was usually 2 years and no more than 4 years, and therefore articles that feature longer term follow-up in comparing CDA with $\mathrm{ACDF}$ would be required for a more complete analysis. Multicenter, long term follow-up RCT studies comparing CDA with $\mathrm{ACDF}$ are also required for inclusion in the analysis.

On the basis of the data acquired in the present study from the mid-term follow-up, it may be concluded that CDA and ACDF are efficient and safe methods for dealing with cervical spondylosis. However, with respect to certain, specific indicators, such as the reoperation rate of adjacent levels following surgery, the former method has several advantages.

\section{References}

1. Wang C, Tian F, Zhou Y, W He and Cai Z: The incidence of cervical spondylosis decreases with aging in the elderly, and increases with aging in the young and adult population: A hospital based clinical analysis. Clin Interv Aging 11: 47-53, 2016.

2. Que Q, Ye X, Su Q, Weng Y, Chu J, Mei L, Huang W, Lu R and Zheng G: Effectiveness of acupuncture intervention for neck pain caused by cervical spondylosis: Study protocol for a randomized controlled trial. Trials 14: 186, 2013.

3. Strine TW and Hootman JM: US national prevalence and correlates of low back and neck pain among adults. Arthritis Rheum 57: 656-665, 2007.

4. Hilibrand AS, Carlson GD, Palumbo MA, Jones PK and Bohlman HH: Radiculopathy and myelopathy at segments adjacent to the site of a previous anterior cervical arthrodesis. J Bone Joint Surg Am 81: 519 528, 1999.

5. Matsumoto M, Okada E, Ichihara D, Watanabe K, Chiba K, Toyama Y, Fujiwara H, Momoshima S, Nishiwaki Y, Iwanami A, et al: Anterior cervical decompression and fusion accelerates adjacent segment degeneration: comparison with asymptomatic volunteers in a ten year magnetic resonance imaging follow-up study. Spine 35: 36-43, 2010.

6. Fernström U: Arthroplasty with intercorporal endoprothesis in herniated disc and in painful disc. Acta Chir Scand Suppl 357: $154-159,1966$

7. Leung C, Casey AT, Goffin J, Kehr P, Liebig K, Lind B, Logroscino $C$ and Pointillart $V$ : Clinical significance of heterotopic ossification in cervical disc replacement: A prospective multicenter clinical trial. Neurosurgery 57: 759-763,2005

8. Malham GM, Parker RM, Ellis NJ, Chan PG and Varma D: Cervical artificial disc replacement with ProDisc-C: Clinical and radiographic outcomes with long-term follow-up. J Clin Neurosci 21: 949-953, 2014.

9. Sasso RC, Anderson PA, Riew KD and Heller JG: Results of cervical arthroplasty compared with anterior discectomy and fusion: Four-year clinical outcomes in a prospective, randomized controlled trial. Orthopedics 34: 889, 2011.

10. Burkus JK, Haid RW, Traynelis VC and Mummaneni PV: Long term clinical and radiographic outcomes of cervical disc replacement with the Prestige disc: results from a prospective randomized controlled clinical trial. J Neurosurg Spine 13: 308-318, 2010.

11. Lau J, Ioannidis JP and Schmid CH: Quantitative synthesis in systematic reviews. Annals of internal medicine 127: 820 826, 1997.

12. Begg CB and Mazumdar M: Operating characteristics of a rank correlation test for publication bias. Biometrics 50: 1088-1101, 1994.

13. Sterne JA, Egger M and Smith GD: Systematic reviews in health care: Investigating and dealing with publication and other biases in meta analysis. BMJ 323: 101-105, 2001.

14. Copas J and Shi JQ: Meta analysis, funnel plots and sensitivity analysis. Biostatistics 1: 247-262, 2000.

15. Leimu R and Koricheva J: Cumulative meta analysis: A new tool for detection of temporal trends and publication bias in ecology. Proc Biol Sci 271: 1961-1966, 2004.

16. Coric D, Kim PK, Clemente JD, Boltes MO, Nussbaum M and James S: Prospective randomized study of cervical arthroplasty and anterior cervical discectomy and fusion with long term follow-up: results in 74 patients from a single site. J Neurosurg Spine 18: 36 42, 2013.
17. Delamarter RB, Murrey D, Janssen ME, et al: Results at 24 months from the prospective, randomized, multicenter Investigational Device Exemption trial of ProDisc C versus anterior cervical discectomy and fusion with 4 year follow-up and continued access patients. SAS journal 4: 122-128, 2010.

18. Garrido BJ, Taha TA and Sasso RC: Clinical outcomes of Bryan cervical disc arthroplasty a prospective, randomized, controlled, single site trial with 48 month follow-up. J Spinal Disord Tech 23: 367-371, 2010.

19. Zigler JE, Delamarter R, Murrey D, Spivak J and Janssen M: ProDisc $\mathrm{C}$ and anterior cervical discectomy and fusion as surgical treatment for single level cervical symptomatic degenerative disc disease: five year results of a Food and Drug Administration study. Spine 38: 203-209, 2013.

20. Murrey D, Janssen M, Delamarter R, et al: Results of the prospective, randomized, controlled multicenter Food and Drug Administration investigational device exemption study of the ProDisc C total disc replacement versus anterior discectomy and fusion for the treatment of 1 level symptomatic cervical disc disease. Spine J 9: 275-286, 2009.

21. Sasso RC, Smucker JD, Hacker RJ and Heller JG: Clinical outcomes of BRYAN cervical disc arthroplasty: a prospective, randomized, controlled, multicenter trial with 24 month follow-up. J Spinal Disord Tech 20: 481-491, 2007.

22. Nabhan A, Ahlhelm F, Shariat K, et al: The ProDisc C prosthesis: clinical and radiological experience 1 year after surgery. Spine 32: 1935-1941, 2007.

23. Zhang HX, Shao YD, Chen Y, et al: A prospective, randomised, controlled multicentre study comparing cervical disc replacement with anterior cervical decompression and fusion. Int Orthop 38: 2533-2541, 2014

24. Zhang X, Zhang Y and Xiao S: Medium and long term result of the single level cervical disc arthroplasty for cervical spondylosis meylopathy. Zhongguo Ji Zhu Ji Sui Za Zhi 22: 879-883, 2012 (In Chinese).

25. Zhang X, Chen C, Zhang Y, et al: Randomized, controlled, multicenter, clinical trial comparing BRYAN cervical disc arthroplasty with anterior cervical decompression and fusion in China. Spine 37: 433-438, 2012.

26. Wang Y, Cai B, Zhang XS, et al: Clinical outcomes of single level Bryan cervical disc arthroplasty: A prospective controlled study. Zhonghua Wai Ke Za Zhi 46: 328-0332, 2008 (In Chinese).

27. Riina J, Patel A, Dietz JW, Hoskins JS, Trammell TR and Schwartz DD: Comparison of single level cervical fusion and a metal on metal cervical disc replacement device. Am J Orthop (Belle Mead NJ) 37: E71-E77, 2008.

28. Phillips FM, Allen TR, Regan JJ, et al: Cervical disc replacement in patients with and without previous adjacent level fusion surgery: A prospective study. Spine 34: 556-565, 2009.

29. Peng-Fei S and Yu-Hua J: Cervical disc prosthesis replacement and interbody fusion: A comparative study. Int Orthop 32: 103-106, 2008.

30. Heller JG, Sasso RC, Papadopoulos SM, et al: Comparison of BRYAN cervical disc arthroplasty with anterior cervical decompression and fusion: clinical and radiographic results of a randomized, controlled, clinical trial. Spine 34: 101-107, 2009.

31. Kim SW, Limson MA, Kim SB, Arbatin JJ, Chang KY, Park MS, Shin JH and Ju YS: Comparison of radiographic changes after ACDF versus Bryan disc arthroplasty in single and bi-level cases. Eur Spine J 18: 218-231, 2009.

32. Goffin J, Geusens E, Vantomme N, Quintens E, Waerzeggers Y, Depreitere B, Van Calenbergh F and van Loon J: Long term follow-up after interbody fusion of the cervical spine. J Spinal Disord Tech 17: 79-85, 2004.

33. Porchet $\mathrm{F}$ and Metcalf NH: Clinical outcomes with the Prestige II cervical disc: Preliminary results from a prospective randomized clinical trial. Neurosurg Focus 17: E6, 2004.

34. Gao Y, Liu M,Li T, Huang F, Tang T and Xiang Z: A meta-analysis comparing the results of cervical disc arthroplasty with anterior cervical discectomy and fusion (ACDF) for the treatment of symptomatic cervical disc disease. J Bone Joint Surg Am 95: 555-561, 2013.

35. Yin S, Yu X, Zhou S, Yin Z, Qiu Y: Is cervical disc arthroplasty superior to fusion for treatment of symptomatic cervical disc disease? A meta analysis. Clin Orthop Relat Res 471: 1904-1919, 2013.

36. Zhang Y, Liang C, Tao Y, Zhou X, Li H, Li F and Chen Q: Cervical total disc replacement is superior to anterior cervical decompression and fusion: A meta-analysis of prospective randomized controlled trials. PLoS One 10: e0117826, 2015. 